4

5

6

7

8

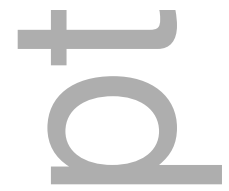

Article type : : General Article

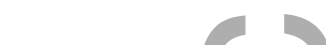

Editorial ref. code: EVJ-GA-19-047.R2

\title{
Complete upper airway collapse and apnoea during tethered swimming in horses
}

\section{S. Jones ${ }^{1 *}$, S. Franklin ${ }^{2}$, C. Martin ${ }^{3}$ and C. Steel ${ }^{1}$}

${ }^{1}$ University of Melbourne Equine Centre, Melbourne, Victoria, Australia; ${ }^{2}$ University of Adelaide Equine Health and Performance Centre, Roseworthy, South Australia, Australia and ${ }^{3}$ Sperero Pty Ltd, Melbourne, Victoria, Australia.

*Corresponding author email: suejonsie@yahoo.co.uk

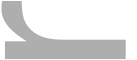

Keywords: horse; swimming; upper airway endoscopy; mammalian dive reflex

Running head: horse, swimming, upper airway endoscopy, mammalian dive reflex

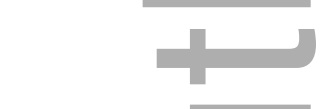

\section{Summary}

Background: There is limited knowledge of the breathing strategy and impact on the patency of the upper respiratory tract (URT) in swimming horses.

Objectives: To describe the respiratory responses and endoscopic appearance of the URT during tethered swimming in horses.

This is the author manuscript accepted for publication and has undergone full peer review but has not been through the copyediting, typesetting, pagination and proofreading process, which may lead to differences between this version and the Version of Record. Please cite this article as doi: $10.1111 / \mathrm{EVJ} .13177$

This article is protected by copyright. All rights reserved 
Study design: Prospective descriptive study.

27

Methods: Ten race-fit horses, with no history of URT obstruction, were examined during tethered swimming. Endoscopic examination, heart rate, sound recordings and above and below water video recordings were obtained. Plasma lactate concentration was measured before and 5 min after swimming and tracheal endoscopy was performed 30 min after exercise to assess for presence of blood or mucus. Four horses also underwent endoscopy during exercise on the track.

Results: Mean ( \pm s.d.) breathing frequency was $28 \pm 5$ breaths/min during swimming, with a brief inspiration (mean \pm s.d. $T_{1}=0.51 \pm .08 \mathrm{~s}$ ), followed by a period of apnoea $(1.59 \pm 0.53 \mathrm{~s})$ and then a short, forced expiration ( $T_{E}=0.42 \pm 0.5 \mathrm{~s}$ ). During apnoea all horses exhibited complete collapse of the URT including closure of the external nares, nasopharynx and rima glottidis (with bilateral adduction of the arytenoid cartilages and vocal folds) and, in two horses, epiglottic retroversion. No horses had URT collapse during overground exercise. Locomotor-respiratory coupling was not observed during swimming. Median (IQR) plasma lactate post-swim was $4.71 \mathrm{mmol} / \mathrm{L}$ (2.08-8.09 $\mathrm{mmol} / \mathrm{L})$ versus $0.68 \mathrm{mmol} / \mathrm{L}(0.65-0.71 \mathrm{mmol} / \mathrm{L})$ pre-swim. Post-swim endoscopy revealed grade 1 exercise-induced pulmonary haemorrhage (EIPH) in 2 horses. Median mucus grade was 1 (range 03).

Main limitations: Overground endoscopy was not performed in all horses.

Conclusions: Horses experienced complete URT collapse associated with post-inspiratory apnoea when swimming. The reason for this is unknown but may be to aid buoyancy or associated with the mammalian dive response - a survival reflex to preserve oxygen stores and prevent water entering the lungs.

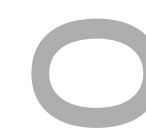

\section{Introduction}

The cardiovascular and, to a limited extent, the respiratory responses to swimming exercise in horses have been described previously [1-5]. The respiratory rate $(R R)$ is considerably lower during swimming (24-48 breaths/min) than during strenuous over ground exercise (approximately 120 breaths/min) [1-3]. The breathing pattern differs from the usual 1:1 breath to stride ratio in galloping horses; however, the description varies between reports [1-5]. The duration of expiration during free swimming has been reported to be approximately twice that of inspiration [1,2]. Others have described three phases of respiration during swimming based on poolside observations: a maximal short inspiration, then a prolonged period of apnoea at full inspiratory volume or an attempted expiration against a closed glottis, followed by a final short "explosive" expiration $[3,5]$. 
Nicholl et al. (1978) further described the period of apnoea as being associated with a raised upper lip, flattening of the alar folds and closure of the airways; however, this observation has not been confirmed by endoscopic examination [3].The effect of swimming on the occurrence of EIPH is also unclear. Swimming-induced pulmonary oedema and haemoptysis is a recognised phenomenon in human athletes $[6,7]$. There are anecdotal reports of horses experiencing epistaxis following swimming $[3,8,9]$, yet the source of the bleeding is uncertain and has been suggested that it arises from the nasopharynx in some cases [9].

Our aim was to describe the respiratory responses in swimming horses and to relate these to endoscopic observations of the upper respiratory tract. A secondary aim was to determine whether EIPH occurred in association with swimming exercise in these horses.

\section{Materials and Methods}

Horses

A convenience sample of 10 race-fit horses (4 Thoroughbreds, 6 Standardbreds; 3 females and 7 geldings; aged 3-10 years), all normal on physical examination and with no recent history of abnormal respiratory noise or exercise-associated epistaxis were used. All had been trained to swim tethered in the pool.

\section{Swimming protocol}

Swimming was conducted in a $25 \mathrm{~m}$ long, $3 \mathrm{~m}$ deep, straight, in-ground pool, which allowed the researchers to access the horse poolside to position the endoscope and view the screen of the heart rate monitor. Each horse was walked into the pool and swam one $25 \mathrm{~m}$ lap on a lead, untethered before data was collected. Tethered swimming (Fig 1) utilised a quick release rubber bungy cord system. This comprised of a rope attached to a quick release metal clasp and bungy tether fixed to a wall approximately 4 metres beyond the entry to the pool. The tail was folded in half and a short rope with a metal ring was tied to the tail so that the metal clasp could be attached. The clasp was in turn secured to the rubber bungy tether. A single handler was responsible for holding both the quick release rope and the head rope. The bungy tether system was attached immediately before the horse was led down the ramp into the pool. Once their hooves no longer contacted the ground, horses were encouraged to swim against the resistance offered by the bungy cord, with each horse exercised for $2 \mathrm{~min}$.

Overground exercise

This article is protected by copyright. All rights reserved 
Four of the eight horses were exercised the following day either under saddle with a jockey $(N=2)$ or in harness $(\mathrm{N}=2)$ depending on the discipline. Horses undertook a routine strenuous exercise session, as determined by the trainer.

Measured variables

Physical examination was performed before, immediately after swimming and at 5 and 30 min postexercise. Recorded parameters included heart rate (HR), RR and rectal temperature (Temp). Heart rate was measured during swimming exercise using two methods: 1 ) a Polar ${ }^{\circledast}$ HR monitor ${ }^{a}$ that was secured to a plait in the mane with electrodes positioned over the thorax in a modified base-apex configuration, and 2) a modified Equivital Lifemonitor ${ }^{\mathrm{b}}$ system, consisting of an extended sensor belt containing three embedded textile based electrodes and a Lifemonitor ${ }^{b}$ sensor electronic module (SEM) placed around the thorax at the girth level (Fig 2). Respiratory sounds were recorded digitally using a microphone $\left(\text { Sony ICD-UX-533F }{ }^{\circledR}\right)^{c}$ and recorder, installed within a sheepskin noseband (Fig 3). Venous samples were taken from the left jugular vein and collected into vacutainers containing sodium fluoride and potassium oxalate before and $5 \mathrm{~min}$ after exercise for measurement of plasma lactate concentration. Samples were centrifuged immediately and stored on ice until they were transported to the laboratory for analysis (COBAS Integra Lact ${ }^{2}$ analyser) ${ }^{d}$. Videos were acquired using a GoPro Hero $3^{\circledR}$ camera $^{\mathrm{e}}$ on a $2 \mathrm{~m}$ long extension pole held underwater and an iPhone $5 \mathrm{~s}^{\oplus \mathrm{f}}$ above the water, both in front of the horse. Devices were chronologically synchronised with recordings started simultaneously.

\section{Endoscopic examination}

Before entering the pool, a nose twitch was applied and a nasogastric tube (16 mm outer diameter; approximately $2 \mathrm{~m}$ in length) was introduced via the left nasal passage approximately $30 \mathrm{~cm}$ so that it was positioned in the rostral nasopharynx. This was tied to the head collar using two, $2.5 \mathrm{~cm}$ wide Penrose drains (Fig 3). Endoscopic examination of the (URT) was performed using a $3 \mathrm{~m}$ gastroscopes. The endoscopy unit was positioned at the side of the pool and the endoscope was introduced via the pre-placed nasopharyngeal tube once the horse had started swimming. On completion of the $2 \mathrm{~min}$ swim the endoscope was removed, the tail tether released, and the horse allowed to swim forward and exit the pool via a ramp. The horses stood in a wash bay until endoscopic examination of the URT and trachea was performed $30 \mathrm{~min}$ after exercise. Tracheal blood and mucus were graded according to previously published scales $[10,11]$.

The overground endoscopic examination was performed using a portable overground endoscope ${ }^{h}$. Following exercise, the horses were hosed down and held in a tie up area until a repeat endoscopic 
examination of the lower airways was performed at 30 min post exercise, as described for horses post-swim.

Data analysis

Heart rate data was uploaded from the SEM to the Equivital software manager for retrospective analysis. Software was used to generate waveforms of the respiratory audio datac which allowed for respiratory timings to be calculated. Total inspiratory duration $\left(T_{1}\right)$, total expiratory duration $\left(T_{E}\right)$ and total apnoeic period were calculated from these graphs, using the mean of six representative breaths for each horse. Video recordings of the swimming gait were viewed in synchrony with respiratory audio recordings and the stride rate and limb timing pattern recorded.

Descriptive analysis of the following data was performed: RR and pattern, Temp, HR and plasma lactate concentrations. Data were assessed for normality using histograms and the Shapiro-Wilk test using Stata version 15.1. Normally distributed data are presented as mean \pm s.d. and non-normally distributed data as median and IQR.

\section{Results}

Two horses were excluded from the study due to refusal to enter the pool $(N=1)$ and panic with a near drowning $(N=1)$ hence the results are reported for eight horses. On entering the water, all horses experienced a period of apnoea of mean duration $18.9 \pm 6.2 \mathrm{~s}$, whereby there were no audible breaths. The onset of apnoea appeared to coincide with the time at which buoyancy was first achieved. During this period there were several brief, low-pitched, barely audible 'grunts' before the first breath, a clearly audible, short expiration (Supplementary Item 1). Six of the eight horses then exhibited the following breathing pattern throughout the remainder of the swim: a short inspiration (mean T, $0.51 \pm 0.10 \mathrm{~s}$ ) followed by a period of apnoea (mean duration $1.61 \pm 0.53$ s) and finally a short, forceful expiration (mean $T_{E} 0.43 \pm 0.06 \mathrm{~s}$ ) (Fig 4b). The remaining two horses adopted a slightly different breathing strategy, whereby they intermittently exhibited a normal breathing pattern for up to four successive breaths in between periods of apnoeic breathing (Fig 4c). The mean \pm s.d. RR for the eight horses was $28 \pm 5$ breaths/min (Supplementary Item 2).

During apnoeic breathing, all eight horses experienced collapse of the external nares with the upper lip drawn upwards (Fig 5) and URT collapse, as observed endoscopically (Fig 6a-f; Supplementary Item 3). Adduction of the arytenoid cartilages and collapse of the vocal folds resulting in closure of the rima glottidis, and circumferential collapse of the nasopharynx, were observed in all cases. Epiglottic retroversion was also observed in two horses; however, this may not have been 
appreciable in the remaining horses due to position of the endoscope. No URT abnormalities were seen during dynamic overground endoscopic examination $(n=4)$.

Respiratory-locomotor coupling was not observed in any horse during swimming. A variety of limb movements were adopted but did not correspond with commonly described terrestrial gaits, including trotting or pacing. Variation in the swimming gait was observed between horses and within the swim session in some horses, but all demonstrated sustained periods of a symmetrical sequence (forelimb (FL)-hindlimb ( $\mathrm{HL}$ )- $\mathrm{FL}_{\text {contralateral }}-\mathrm{HL}_{\text {contralateral }}$ ) which we described as a disunited pace with the protraction and retraction phases of movement of each HL slightly delayed compared to the protraction and retraction movements of the ipsilateral FL (Supplementary Item 4).

Post-swim endoscopy revealed that all horses had pharyngeal contusions that were suspected to have been caused by the nasopharyngeal tube and endoscope. Seven of the eight horses had tracheal mucus and two horses had grade 1 tracheal blood (Supplementary Items 5 and 6). Both horses with evidence of tracheal blood were those that demonstrated an intermittently more normal respiratory pattern whilst swimming. On examination $30 \mathrm{~min}$ after overground endoscopy, all horses also had some degree of pharyngeal trauma, two horses had tracheal mucus and two had grade 1 tracheal blood, one of which had also had grade 1 tracheal blood after swimming (Supplementary Item 5).

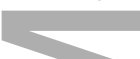

Plasma lactate was increased in all horses post-swim (median $6.97 \mathrm{mmol} / \mathrm{L}$; range $0.73-25.3 \mathrm{mmol} / \mathrm{L}$ ) compared to pre-swim (median $0.73 \mathrm{mmol} / \mathrm{L}$; range 0.61-1.22 mmol/L; Supplementary Item 2). Maximum HR recorded by the Equivital Lifemonitor ${ }^{b}$ during swimming ranged from 100 b.p.m. to 216 b.p.m.; however, due to technical failure of the $\mathrm{Polar}^{\circledR}$ watch $^{\mathrm{a}}$ these results could not be corroborated. The HR at 5 min post swimming ranged from 84 b.p.m. to 183 b.p.m (Supplementary Item 2). In two horses undiagnosed arrhythmias were evident immediately after exiting the pool and persisted at $5 \mathrm{~min}$ but were resolved by $30 \mathrm{~min}$ post- exercise. There was no significant difference in body temperature before and after swimming (Supplementary Item 2).

\section{Discussion}

Although commonly used in the training of Thoroughbred and Standardbred racehorses in countries with warmer climates such as Australia, potential beneficial and adverse effects of swimming as an adjunct or substitute for traditional land-based exercise are unclear [12]. All horses experienced periods of post-inspiratory apnoea ('breath-holding') during swimming exercise. This coincided with flattening of the external nares, complete closure of the rima glottidis and collapse of the 
nasopharynx. Four of these horses were found to have normal upper airway function during overground exercise. The reason for periods of breath holding during swimming and whether this is under voluntary or autonomic control is unclear. We propose that it may be a mechanism to aid buoyancy and, at least to some extent, be a manifestation of the mammalian dive reflex (MDR).

A component of the MDR has been suspected to play a role in the adopted respiratory pattern of swimming horses as early as 1977 where swimming was suspected to initiate a "protective diving reflex" [13]. The MDR has been reported in a variety of terrestrial vertebrates $[14,15]$ and is characterised by apnoea, profound bradycardia and re-directing of blood flow away from nonexercising muscles and organs. This primarily occurs in response to hypercapnia but seems to be instigated by many overlapping reflexes including the trigemino-cardiac reflex, triggered by the afferent sensory nerves in the head and neck, particularly the face, nose and larynx in humans [15]. The MDR can be recreated in humans with only the face submerged [16]. It is a powerful autonomic reflex, over-riding the homeostatic respiratory chemoreceptor reflex. It has been suggested that breath holding in the face of hypoxia and hypercapnia, is a reflex to preserve life, a fundamental response to asphyxia [17]. The reflex has a complex and poorly understood initiation but is thought to be at least partially due to stimulation of the afferent trigeminal neural pathway [14]. While the MDR is recognised in many species, the degree of response is variable even intra species where cortical factors such as voluntary or involuntary diving appear to have an impact on the degree of bradycardia [18]. The horses' response may also be less intense due to it evolving as a primary terrestrial animal. Immediately post swimming we observed an increased respiratory effort. We postulate that this could be related to an accumulated oxygen debt and/or hypercapnia associated with tethered swimming [19].

Breath holding is observed in aquatic and semi-aquatic species at rest at the water surface with all animals demonstrating a lower RR when in water [20]. A similar reduction in RR occurred in horses in the current study and has been reported previously $[2,13,21]$. The hippopotamus was described to breath hold for over one minute with its head immersed when in water that was deeper than it could stand and this was proposed to occur to aid buoyancy [20]. Post-inspiratory apnoea in semiaquatic mammals, like the seal, enables the maintenance of lung volume above functional residual capacity [22], which in addition to blubber is thought to contribute to buoyancy, certainly at the water surface. Hobo et al. observed what they thought to be a prolonged expiratory time in swimming horses and suggested that this prevented a significant decrease of air volume thereby contributing to buoyancy [1]. We did not observe a prolonged expiratory time, but rather a short 'explosive' expiration after a period of breath holding during which there was URT collapse, yet 
agree that this breathing pattern may still be a mechanism to aid buoyancy during swimming by maximising lung volume.

221 A prominent feature of the MDR is bradycardia. Due to technical issues we were unable to confirm 222 bradycardia in this study. The Equivital ${ }^{b}$ system obtains a HR from a base apex electrocardiogram 223 (ECG) tracing and has been validated in the horse at rest and submaximal exercise (Verdegaal and 224 Franklin; personal communication). Although the HR values acquired using this system were similar 225 to those previously reported $[1,21,23,24]$, when we visualised the ECG tracings, complex formation was not clear and as a result we are unsure of the validity. Furthermore, we were unable to corroborate the values with those from the polar monitor due to technical issues.

Other studies have recorded maximum HR ( $\left.H R_{\max }\right)$ of 182-195 b.p.m. following six 50 metre laps [1], 145-178 b.p.m. during a $20 \mathrm{~min}$ swim [21] and 144-203 b.p.m. during a continuous swim [23]. These heart rates are lower than $H R_{\max }$ recorded in galloping Thoroughbreds of $215 \pm 2 \mathrm{bpm}$ [25] and trotting Standardbreds of $216 \pm 9 \mathrm{bpm}$ [26]. The lower HR may be a reflection of lower exercise intensity compared with overground exercise or may suggest that horses do indeed experience a degree of bradycardia during swimming exercise. Improved venous and lymphatic return due to surrounding water pressure and peripheral vasoconstriction in cool water may also contribute to lower $\mathrm{HR}_{\max }$ during swimming, as appreciated in humans [27], and make comparison of the intensity of swimming and overground exercise difficult.

237 The elevations in plasma lactate concentrations post swimming suggest that the exercise intensity was indeed strenuous, necessitating an anaerobic component. However, it is also possible that this may be related to the hypoventilation experienced by swimming horses, as indicated by the decreased respiratory rate. In this study, plasma lactate concentrations were similar to those previously reported after swimming [24], and in all but one horse were lower than those typically seen with overground exercise, suggesting that swimming exercise is not as strenuous as overground exercise $[24,28]$. Measurements of plasma lactate post swim were highly variable between horses. One horse had a post swim lactate of $25.3 \mathrm{mmol} / \mathrm{L}$ that was similar to that measured following over ground exercise $(26.74 \mathrm{mmol} / \mathrm{L})$. This horse was one of two that intermittently demonstrated a more normal breathing pattern. The horse was also noted to have an undiagnosed tachyarrhythmia after swimming and overground exercise. The second horse had a post swim lactate of $7.69 \mathrm{mmol} / \mathrm{L}$ but was not exercised over ground.

The 1 to 1 locomotor-respiratory coupling (LRC) ratio observed when galloping [29] suggest that voluntary control of breathing does not occur at this gait. However, this does not occur in trotting or pacing horses which may adopt a variety of LRC ratios [30]. In our study, LRC was not observed in 
horses during swimming. The most consistent gait demonstrated could be described as a disunited pacing-like gait with the timing of retraction of the ipsilateral HL slightly delayed. This gait is similar to the swimming gait of dogs with an ipsilateral footfall sequence $\left(\mathrm{FL}-\mathrm{HL} \mathrm{L}_{\text {ipsilateral }}-\mathrm{FL}_{\text {contralateral }}{ }^{-}\right.$ $\mathrm{HL}_{\text {contralateral) }}$ [31]. The adaptive inter-segmental limb coordination exhibited by mammals during swimming has been suggested to be an intrinsic evolutionary conservation of ancestral biomechanical and neurophysiological neural pathways [32]. The implications of exercise using a different gait timing pattern and presumably recruiting muscles differently to overground exercise is unknown and warrants further investigation.

Grade 1 blood was observed in the distal trachea post-swimming in two horses, indicating EIPH. However, the sample size was too small to make conclusions on the frequency of EIPH during swimming exercise. Bronchoalveolar lavage pre and post exercise may have proven useful in the assessment of low grade EIPH but were not performed in this study. Jones et al. [2] measured higher intrapleural pressures during free swimming compared to during galloping exercise on the treadmill. Peak expiratory pressure was $9.9 \mathrm{kPa} \pm 0.7 \mathrm{kPa}$ during swimming compared to $3.5 \pm 0.7 \mathrm{kPa}$ during galloping at 13-14 m/s). In contrast, inspiratory pressures were less negative during swimming (-2 \pm $0.8 \mathrm{kPa})$ compared with galloping exercise $(-3.9 \pm 0.4 \mathrm{kPa})$. Tracheal pressures were measured in another study [33] and, again, expiratory values were greater than previously reported during galloping exercise. Hobo et al. [1] recorded higher peak expiratory pressures (approximately $5.1 \mathrm{kPa}$ ) during swimming than previously reported during treadmill exercise (1.47-2.74 kPa at $14 \mathrm{~m} / \mathrm{s}$ ) [34]. However, inspiratory pressures $(-4.5 \pm 1.5 \mathrm{kPa})$ were similar to those reported during treadmill exercise $(-3.92$ to $-4.9 \mathrm{kPa})[1,34]$.

This study had several limitations. In addition to our inability to validate HR data during swimming, horses had to be tethered so that endoscopic examination could be performed. Although we expect that similar URT collapse and lack of LRC occurs during free swimming, this remains to be determined. We used horses in race training and dynamic endoscopic examination overground was only possible in four of the eight horses. However, there was no history of abnormal respiratory noise in the remaining 4 horses.

Swimming is commonly used for racehorses in training [35] but the findings of this study may raise concerns regarding health implications to swimming horses. Based on our observations, we would not recommend swimming horses with impaired upper airway function as they may be unable to fully protect their airway. Future studies may also assess the stress response to swimming exercise through the use of ethograms or assessment of physiological markers such as cortisol, HRV and/or eye temperature [36-38]. 
287 The breathing strategy used during tethered swimming is different from that during overground exercise, with complete collapse of the URT occurring in association with apnoea during each respiratory cycle and lack of LRC. Mechanisms are poorly understood but these responses may be a survival strategy, as in a manifestation of the MDR or may be a mechanism to aid buoyancy. Implications for the training, health and welfare of horses are currently unclear and warrant further investigation.

\section{Authors declaration of interest}

No competing interests have been declared.

\section{Ethical animal research}

This study was approved by the Animal Ethics Committee (1614079.1).

299

\section{Owner informed consent}

Owners gave consent for their animals' inclusion in the study.

302

\section{Source of funding}

304

None.

305

\section{Acknowledgements}

The authors thank Andrew Walker, Alex MacPherson and Fiona Armour for their assistance with the completion of this study.

\section{Authorship}

S. Jones, C. Steel and S. Franklin were all involved in the design and inception of the study design. All authors were involved in data collection on site and interpretation of findings. C. Martin contributed equipment for data collection including subsequent software for data analysis. S. Jones wrote the first draft of the manuscript and made changes suggested by the other authors. All authors approved the final version of the manuscript. 
aPolar, Kempele, Finland.

320 bequivital EQ02, Hidalgo, UK.

321 'Sony, Tokyo, Japan.

322 dRoche Diagnostics, Julius Avenue, Sydney, Aus.

323 eGoPro, San Mateo, California, USA.

$324{ }^{\mathrm{f}}$ Apple, California, USA.

325 gAohua ${ }^{\circledR}$ Shanghai, China.

326 hVideomed GmbH., München, Germany.

327 iSony Software, Tokyo, Japan.

328

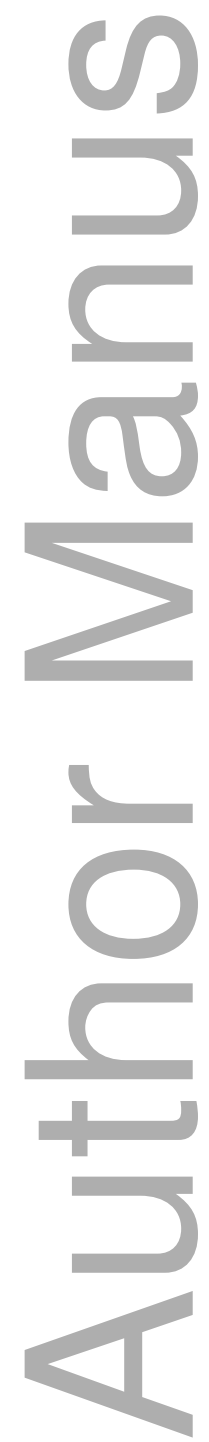

This article is protected by copyright. All rights reserved 
Fig 1: Rubber bungy cord quick release system secured to tail before entering the pool. Researchers could access the horse directly from pool-side.

Fig 2: Electrocardiogram belt adapted from the human Equivital ECG vest (Hidalgo ${ }^{b}$ ) demonstrating electrode placement on the equine trunk.

Fig 3: The microphone is housed within the sheepskin nose band. The endoscope is in place within a preplaced nasopharyngeal tube.

Fig 4: a) Normal inspiration (ins) to expiration (exp). b)Breathing pattern demonstrated by all horses $(\mathrm{bh}=$ breath hold $)$. c) Breathing pattern occasionally adopted by two horses.

Fig 5: External appearance of flattening of nares.

Fig 6: $a-f)$ Progressive adduction of the arytenoid cartilages, closure of the rima glottidis and pharyngeal collapse as seen endoscopically in all horses

\section{Supporting Information}

Supplementary Item 1: Sound recording of breathing pattern during swimming exercise.

Supplementary Item 2: Physical examination and lactate results.

Supplementary Item 3: Endoscopic video of the URT in swimming horse.

Supplementary Item 4: Below water video of swimming horse.

Supplementary Item 5: Endoscopic findings.

Supplementary Item 6: Grading scales for mucus and EIPH.

References

[1] Hobo, S, Yoshida, K. and Yoshihara, T. (1998) Characteristics of respiratory function during swimming exercise in thoroughbreds. J. Vet. Med. Sci. 60, 687-689. 
[2] Jones, J.H., Cox, K.S., Takahashi, T., Hiraga, A., Yarbrough, T.B. and Pascoe, J.R. (2002) Heterogeneity of intrapleural pressures during exercise. Equine Vet. J. 34, Suppl. 34, 391396.

[3] Nicholl, T.K., Fregin, G.F. and Gerber, N.H. (1978) Swimming - A method to study the physiologic response of the horse to exercise. J. S. Afr. Vet. Assoc. 49, 313-315.

[4] Garcia M. C. and Beech, J. (1986) Endocrinologic, hematologic, and heart rate changes in swimming horses. Am. J. Vet. Res. 47, 2004-2006.

[5] Thomas, D.P., Fregin, G.F., Gerber, N.H. and Ailes, N.B. (1980) Cardiorespiratory adjustments to tethered-swimming in the horse. Pflugers Arch. 385, 65-70.

[6] Bove, A.A. (1996) Medical aspects of sports diving.

[7] Grünig, H., Nikolaidis, P.T., Moon, R.E. and Knechtle, B. (2017) Diagnosis of Swimming Induced Pulmonary Edema-A Review. Frontiers in Physiology 8, 652.

[8] Erickson, B., Erickson, H. and Coffman, J. (1990) Pulmonary artery, aortic and oesophageal pressure changes during high intensity treadmill exercise in the horse: a possible relation to exercise-induced pulmonary haemorrhage. Equine Vet. J. 22, 47-52.

[9] Jones, J. and Hiraga, A. (2008) Metabolic, cardiovascular and respiratory responses to swimming in horses. In: Proceedings of a Workshop on. p 34.

[10] Gerber, V., Straub, R., Marti, E., Hauptman, J., Herholz, C., King, M., Imhof, A., Tahon, L. and Robinson, N. (2004) Endoscopic scoring of mucus quantity and quality: observer and horse variance and relationship to inflammation, mucus viscoelasticity and volume. Equine Vet. J. 36, 576-582. 
387

388

389

390

391

392

393

394

395

396

397

398

399

400

401

402

403

404

405

406

407

408

409

410

411

412

[11] Hinchcliff, K.W., Jackson, M.A., Brown, J.A., Dredge, A.F., O'Callaghan, P.A., McCaffrey, J.P., Morley, P.S., Slocombe, R.F. and Clarke, A.F. (2005) Tracheobronchoscopic assessment of exercise-induced pulmonary hemorrhage in horses. Am. J. Vet. Res. 66, 596-598.

[12] Davie, A., Savage, C. and Fennel, L. (2008) The effect of swimming training on the cardiac dimensions in thoroughbred horses. RIRDC Publication No. 08/156.

[13] Fregin, G.F. and Nicholl, T. (1977) Swimming: Its influences on heart rate, respiration rate and some hematological values in the horse.

[14] McCulloch, P., Ollenberger, G., Bekar, L. and West, N. (1997) Trigeminal and chemoreceptor contributions to bradycardia during voluntary dives in rats. Am. J. Physiol. 273, R814-R822.

[15] Oppenheimer, S. (2013) Human's association with water bodies: The 'Exaggerated Diving Reflex'and its relationship with the evolutionary allometry of human pelvic and brain sizes. Hum. Evol. 28, 137-170.

[16] Hagen, J.B. (2018) The diving reflex and asphyxia: Working across species in physiological ecology. History and philosophy of the life sciences 40, 18.

[17] Panneton, W.M. (2013) The mammalian diving response: an enigmatic reflex to preserve life? Physiology (Bethesda) 28, 284-297.

[18] McCulloch, P. (2012) Animal Models for Investigating the Central Control of the Mammalian Diving Response. Frontiers in Physiology 3, 169.

[19] Milne D. W., M.W.W., Skarda R. T., Fregin G. F., Nicholl J. K. (1977) The hemodynamic response of the horse to swimming with and without furosemide. J. Equine Med. Surg. 1, 331-335.

This article is protected by copyright. All rights reserved 
[20] Mortola, J.P. and Limoges, M.-J. (2006) Resting breathing frequency in aquatic mammals: a comparative analysis with terrestrial species. Respir. Physiol. Neurobiol. 154, 500-514.

[21] Murakami M., I.T., Inui T., Amada A., Senta T., Takagi S., Kubo K., Sugimoto O., Watanabe H., Ikeda S., Kameya T. (1976) Swimming exercise in horses. Exp. Rep. Equine HIth. Lab. 27-49.

[22] Mortola, J.P. and Lanthier, C. (1989) Normoxic and hypoxic breathing pattern in newborn grey seals. Can. J. Zool. 67, 483-487.

[23] Asheim, A., Knudsen, O., Lindholm, A., Rülcker, C. and Saltin, B. (1970) Heart rates and blood lactate concentrations of standardbred horses during training and racing. J. Am. Vet. Med. Assoc. 157, 304-312.

[24] Klomp, M., Munsters, C.C. and van Oldruitenborgh-Oosterbaan, M.M.S. (2014) Swimming exercise and race performance in Thoroughbred racehorses. Pferdeheilkunde 30, 403-406.

[25] Vermeulen, A. and Evans, D. (2006) Measurements of fitness in thoroughbred racehorses using field studies of heart rate and velocity with a global positioning system. Equine Vet. J. 38, 113-117.

[26] Lindner, A. (2010) Relationships between racing times of Standardbreds and v4 and v200. J. Animal Sci. 88, 950-954.

[27] Lazar, J.M., Khanna, N., Chesler, R. and Salciccioli, L. (2013) Swimming and the heart. Intern. J. Cardiol. 168, 19-26.

[28] Misumi K., S.H., Shimizu R. (1994) Changes in blood lactate and heart rate in thoroughbred horses during swimming and running according to their stage of training. Vet. Rec. 135, 226228. 
[29] Bramble, D.M. and Carrier, D.R. (1983) Running and breathing in mammals. Science 219, 251-256.

[30] Cottin, F., Metayer, N., Goachet, A., Julliand, V., Slawinski, J., Billat, V. and Barrey, E. (2010) Oxygen consumption and gait variables of Arabian endurance horses measured during a field exercise test. Equine Vet. J. 42, Suppl. 38, 1-5.

[31] Catavitello, G., Ivanenko, Y.P. and Lacquaniti, F. (2015) Planar covariation of hindlimb and forelimb elevation angles during terrestrial and aquatic locomotion of dogs. PloS one 10, e0133936.

[32] Meyns, P., Bruijn, S.M. and Duysens, J. (2013) The how and why of arm swing during human walking. Gait \& Posture 38, 555-562.

[33] Rehder, R., Ducharme, N., Hackett, R. and Nielan, G. (1995) Measurement of upper airway pressures in exercising horses with dorsal displacement of the soft palate. Am. J. Vet. Res. $56,269-274$.

[34] Ducharme, N., Hackett, R., Ainsworth, D., Erb, H. and Shannon, K. (1994) Repeatability and normal values for measurement of pharyngeal and tracheal pressures in exercising horses. Am. J. Vet. Res. 55, 368-374.

[35] Steel, C., Bond, B. and Morrice-West, A. (2019) Survey of trainers on the use of swimming exercise for Standardbred racehorses in Australia. Aust. Vet. J. 97, 61-67.

[36] Borstel, U.K.v., Visser, E. and Hall, C. (2017) Indicators of stress in equitation. Appl. Animal Behav. Sci. 190, 43-56.

[37] Kaiser, L., Heleski, C.R., Siegford, J. and Smith, K.A. (2006) Stress-related behaviors among horses used in a therapeutic riding program. J. Am. Vet. Med. Assoc. 228, 39-45. 


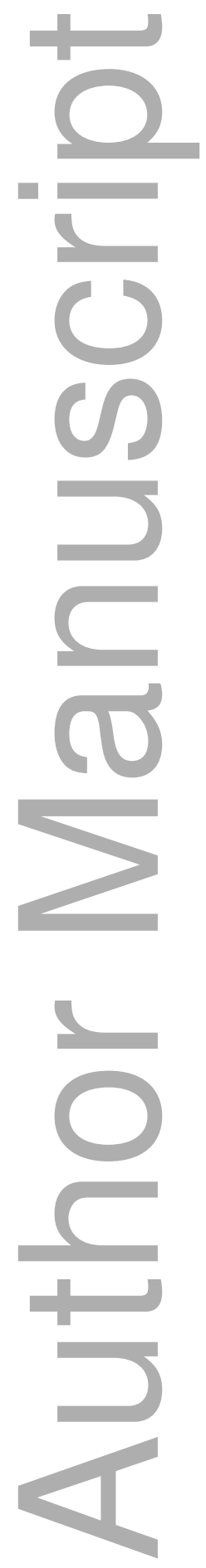




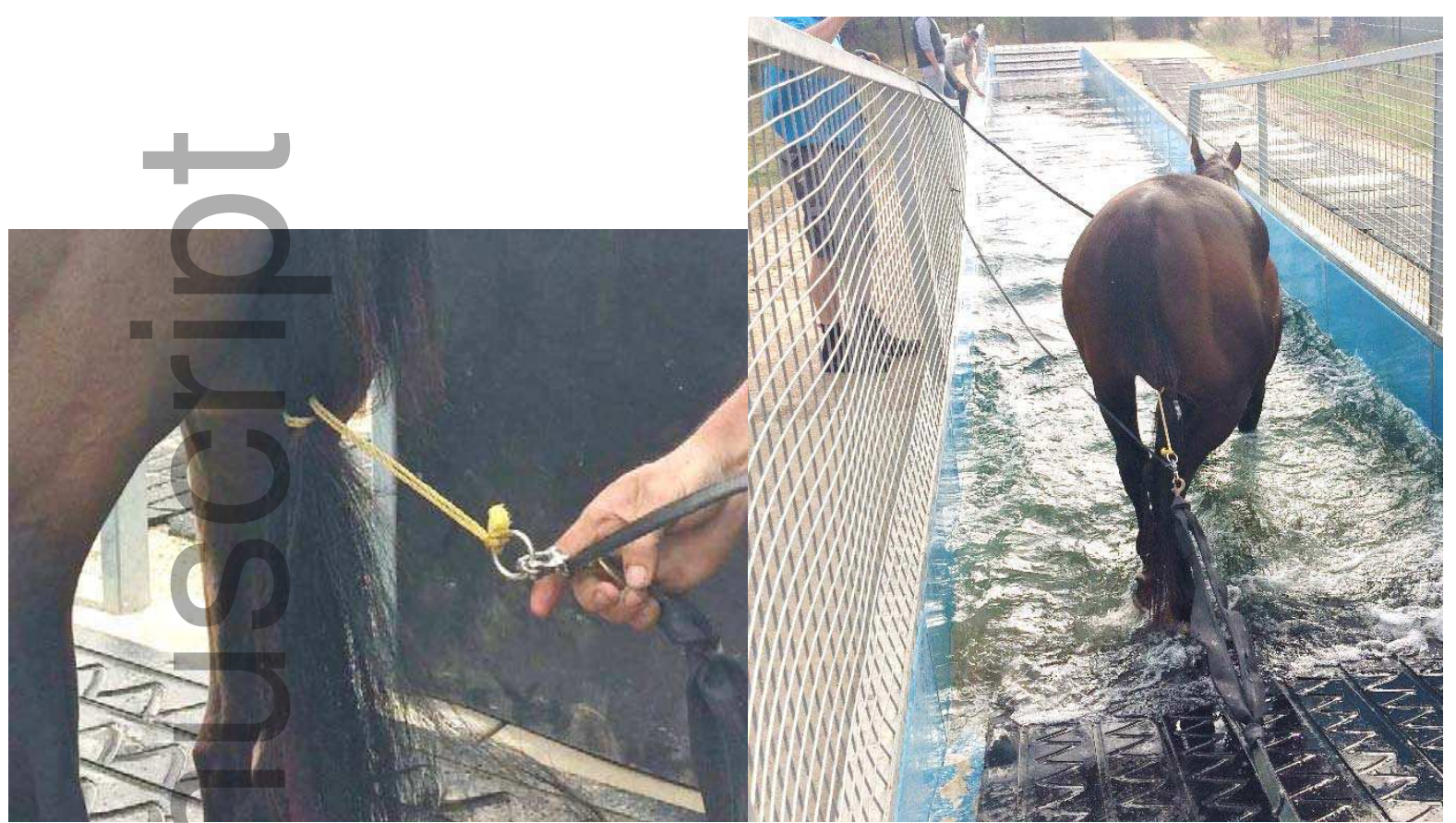

Figure 1. Rubber bungy cord quick release system secured to tail before entering the pool. Researchers could access the horse directly from pool-side.
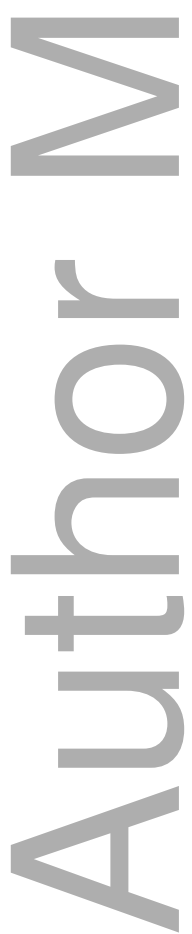

This article is protected by copyright. All rights reserved 


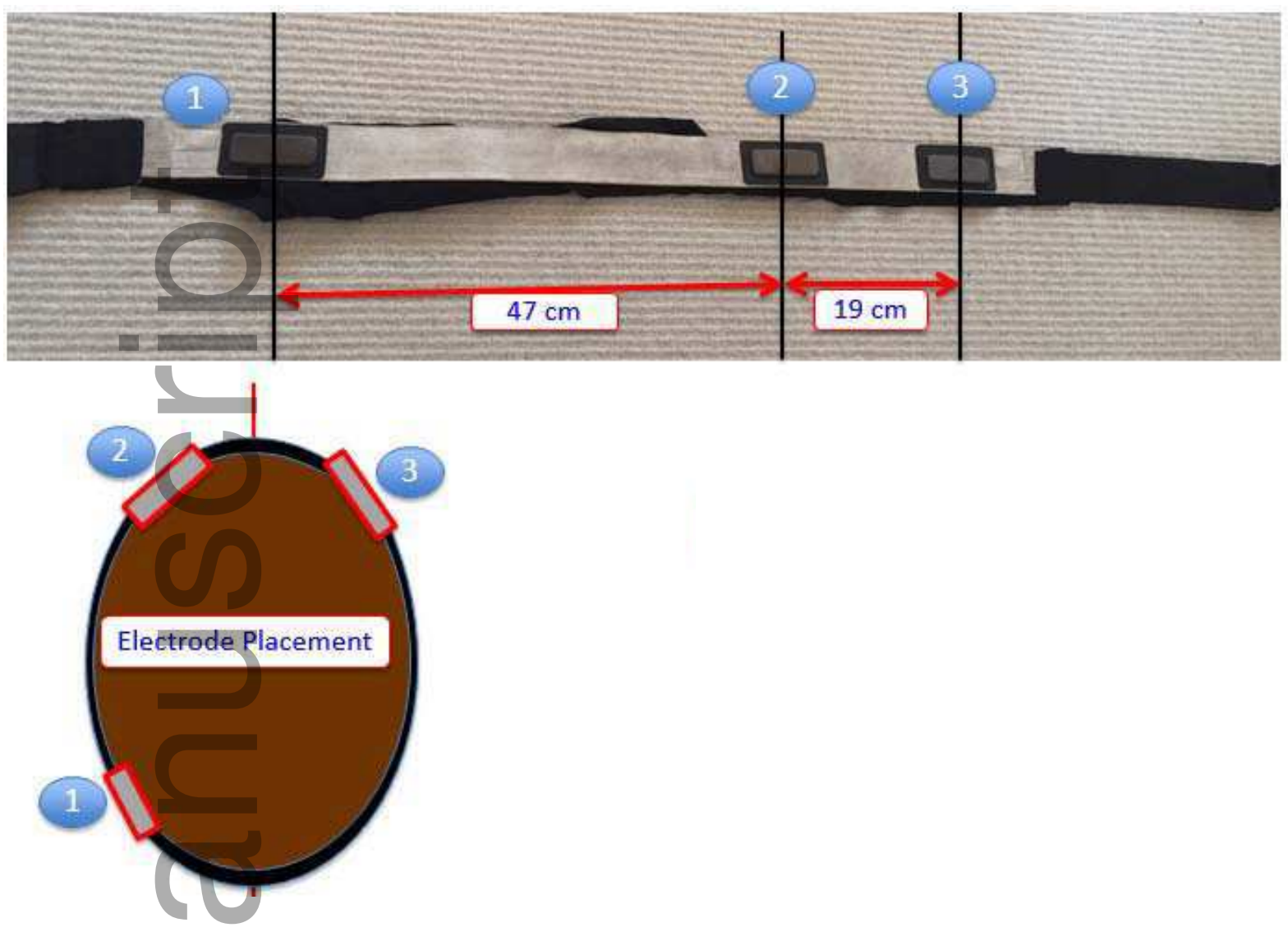

Figure 2. Electrocardiogram belt adapted from the human Equivital ECG vest (Hidalgo ${ }^{\text {b }}$ ) demonstrating electrode placement on the equine trunk

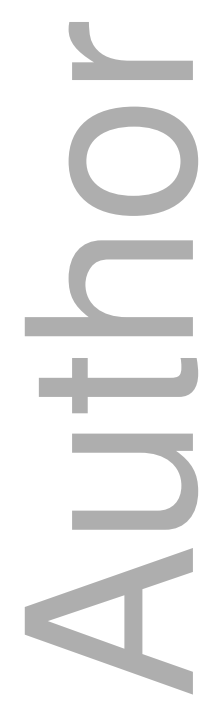

This article is protected by copyright. All rights reserved 


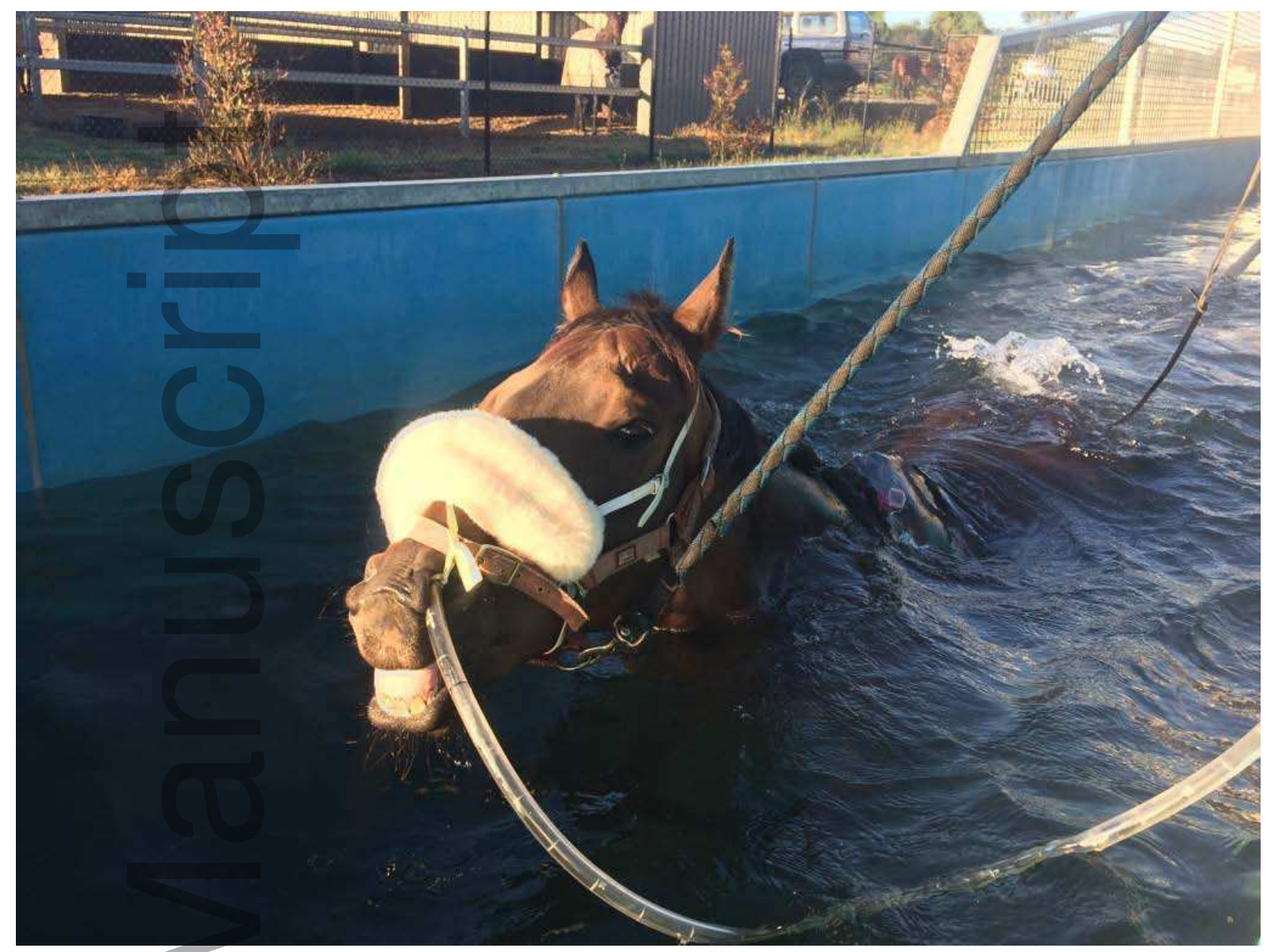

Figure 3. The microphone is housed within the sheepskin nose band. The endoscope is in place within a preplaced nasopharyngeal tube.

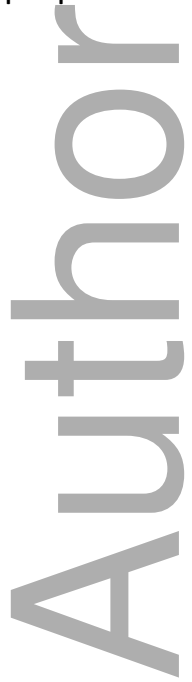

This article is protected by copyright. All rights reserved 


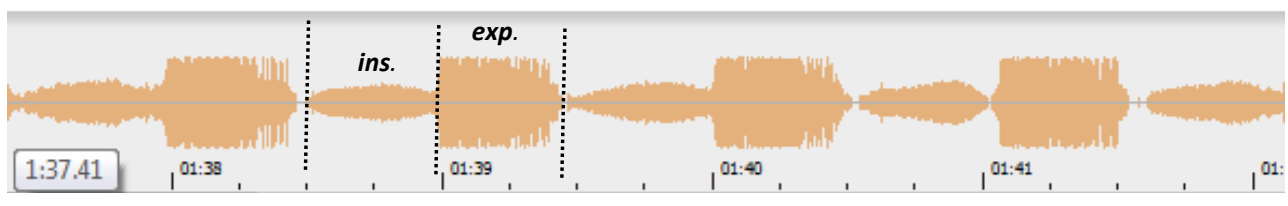

Figure 4a. Normal inspiration (ins) to expiration (exp).

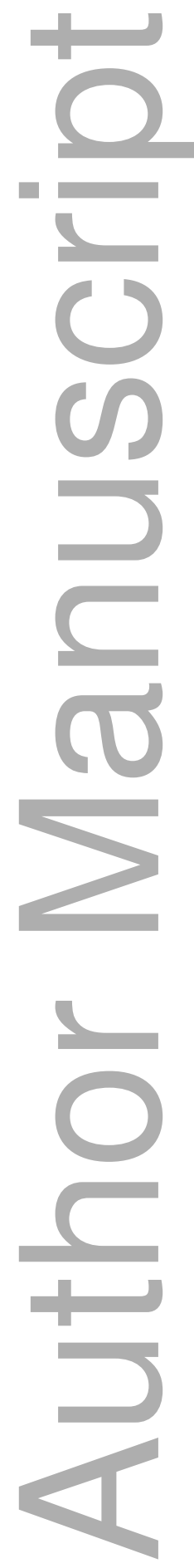

This article is protected by copyright. All rights reserved 


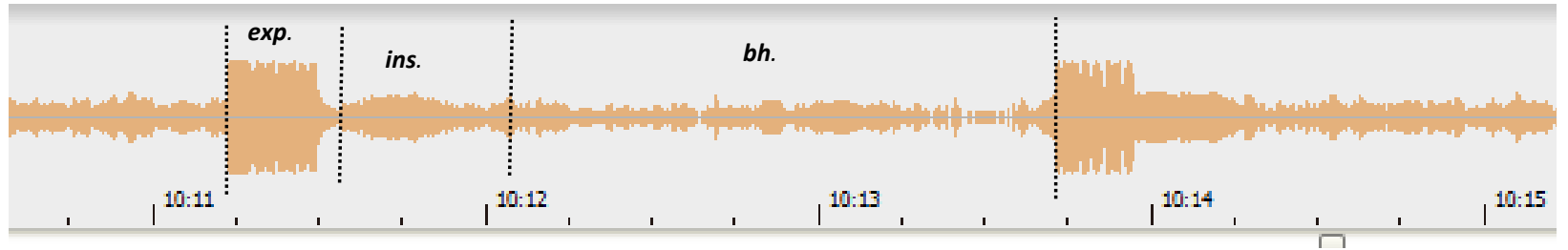

Figure 4b. Breathing pattern demonstrated by all horses (bh= breath hold).

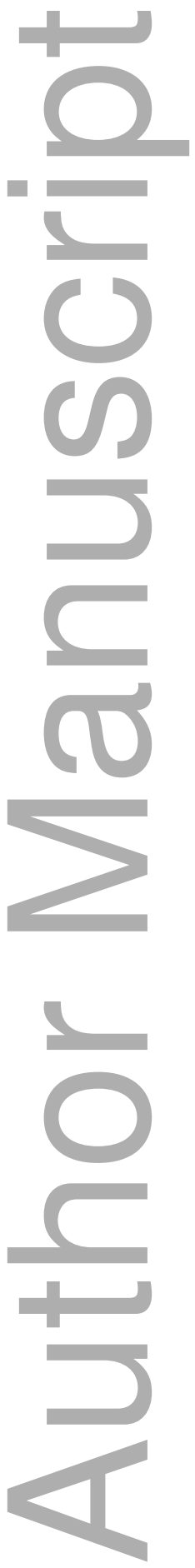

This article is protected by copyright. All rights reserved 


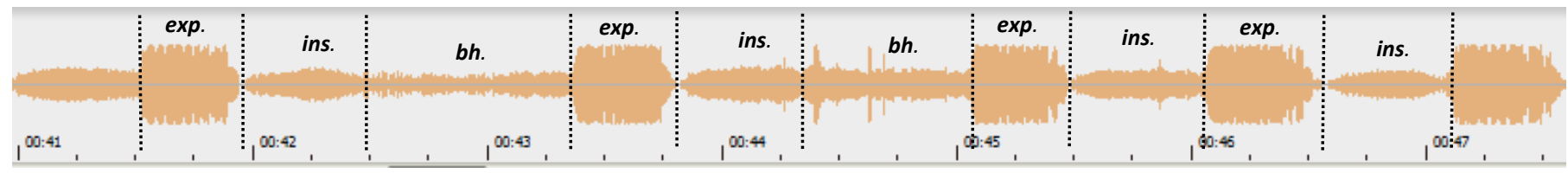

Figure 4c. Breathing pattern occasionally adopted by two horses

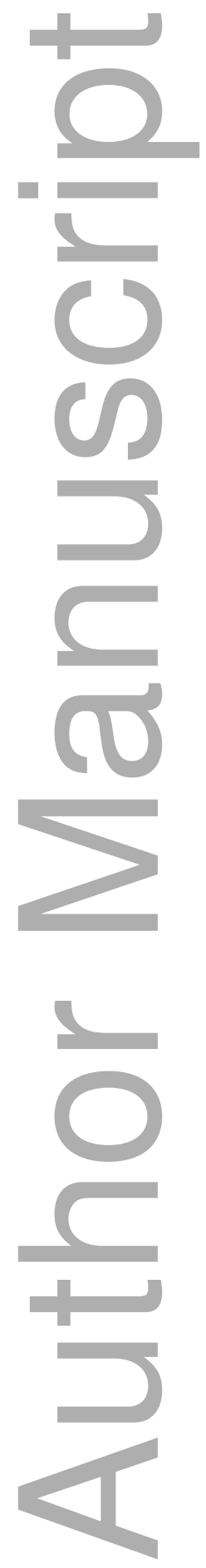

This article is protected by copyright. All rights reserved 


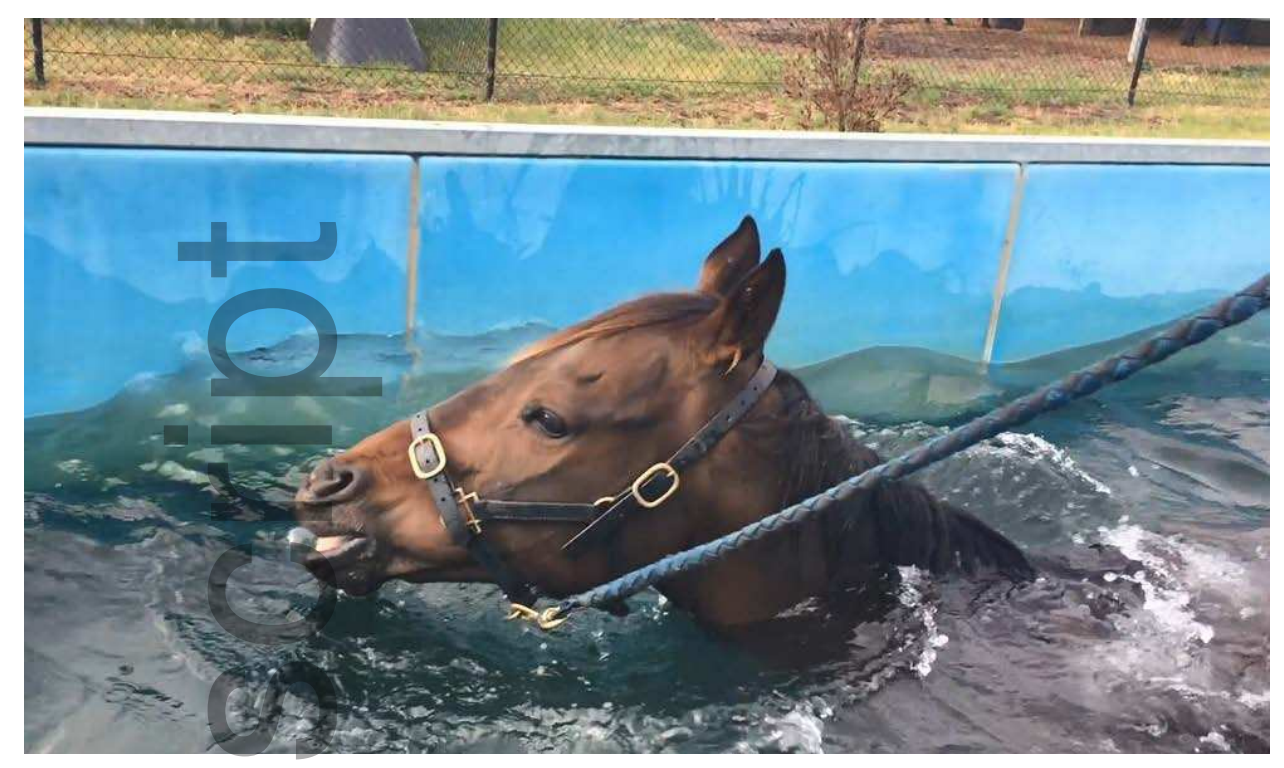

Figure 5. External appearance of flattening of nares

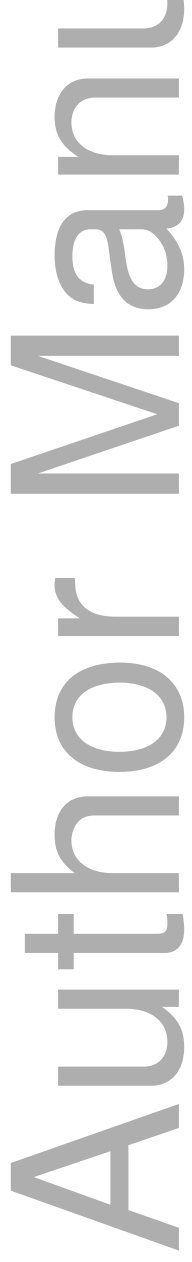

This article is protected by copyright. All rights reserved 

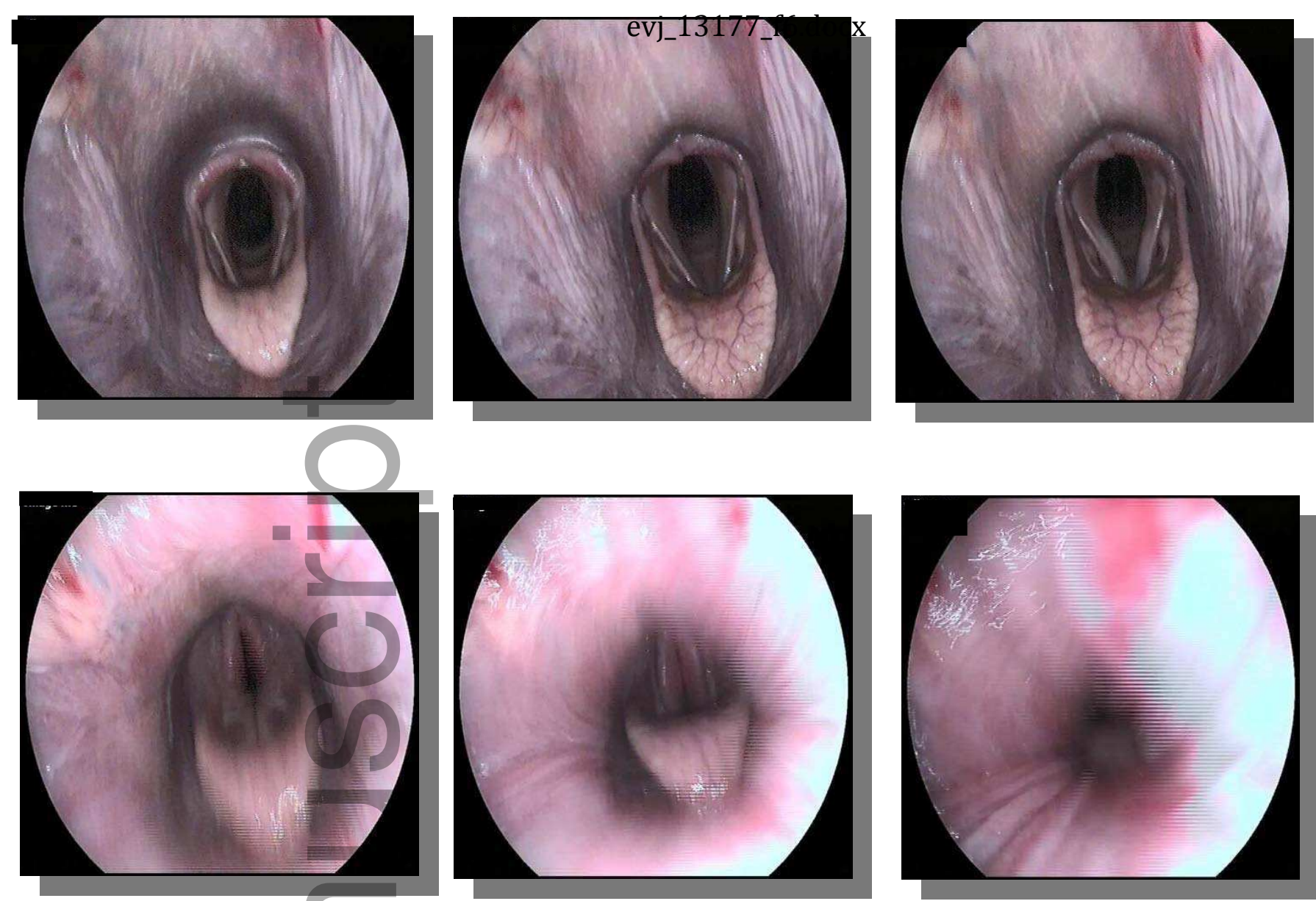

Figure $6 \mathrm{a}-\mathrm{f}$. Progressive adduction of the arytenoid cartilages, closure of the rimma glottidis and pharyngeal collapse as seen endoscopically in all horses

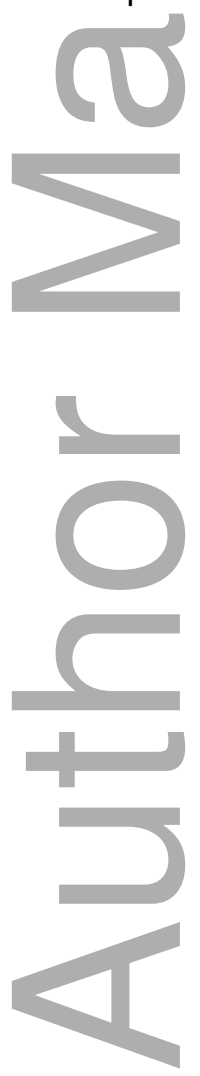

This article is protected by copyright. All rights reserved 


\section{University Library}

\section{- M M I N E R VA A gateway to Melbourne's research publications}

Minerva Access is the Institutional Repository of The University of Melbourne

\section{Author/s:}

Jones, S;Franklin, S;Martin, C;Steel, C

Title:

Complete upper airway collapse and apnoea during tethered swimming in horses.

Date:

2020-05

Citation:

Jones, S., Franklin, S., Martin, C. \& Steel, C. (2020). Complete upper airway collapse and apnoea during tethered swimming in horses.. Equine Vet J, 52 (3), pp.352-358. https:// doi.org/10.1111/evj.13177.

Persistent Link:

http://hdl.handle.net/11343/286486 